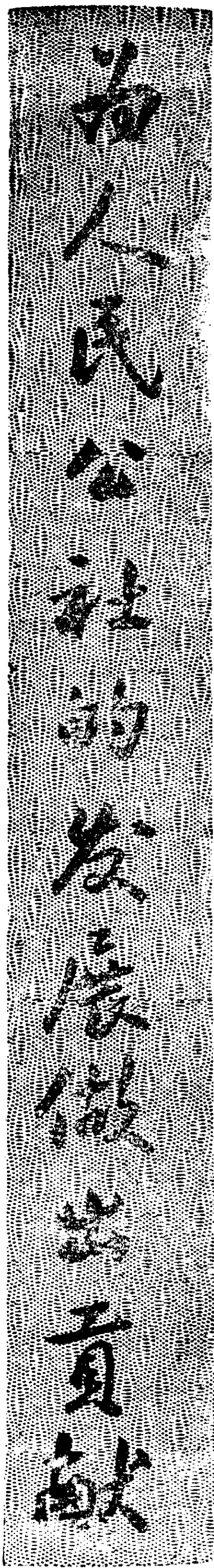

\title{
开展人民公社的調查研究 建立新經济地理学
}

吳 傅 鈞

（中国科学院地理研觉所）

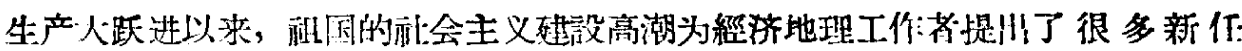

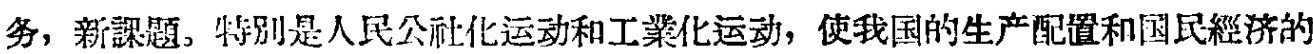

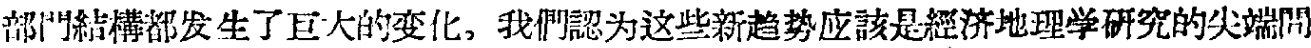
邀。經济地理学如同所有的科学一样, 它的发展必須結合任务。人民公社的建立., 农 倠方面基本农田制的实行，工業方面大、中、小結合的配瞋原则，都是我国所独㓣， 研究这些間題可以为我国經济地理学开辟一条全新的道路。

特别是有关人民公部这一新的社会組絨的經济地理的研究內容是異常丰富的，这

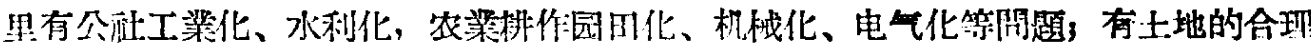
利月問題; 有工、农、林、牧、副、海多和生产配置和綜合发展的開题，有居民点、 交通网、河道网的配置問題; 有大比例尺經济地图的䋧例問題; 有綜合性的開題，也

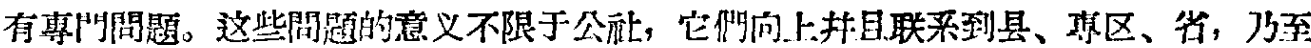

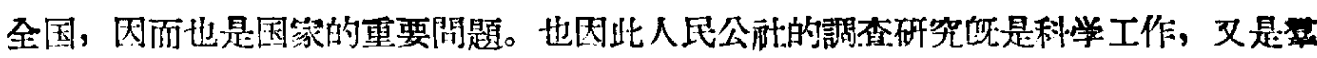
众性的政治經济工作。能够参㧈到这項工作中去，是地理工作者莫大的光荣任务。

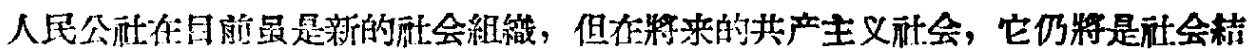

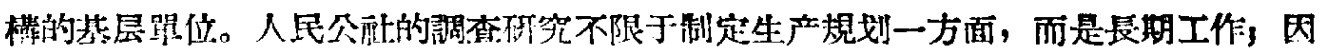
为生产規划的制定只是为公融生产发展远景画似了一幅籃图, 而人民公社作为生产棕 合体，住它的形成和发展过程中会不断H現新的開題、新的規律，因此我們，必须調度 較多的力量配合这一任务，零門从事这方面的研究。我們可以这样肯定: 今后我們程 济地理学的发展以人民公形的研究任务为綱, 以此带动各部师經济地理学刢造性的发

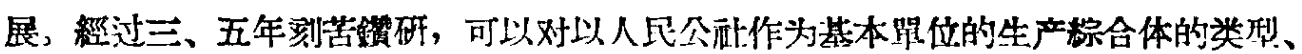

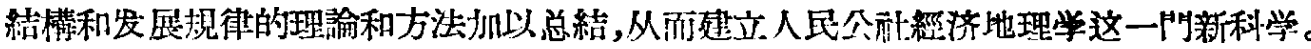
这“临科学是我国經济地理学的生長点; 通过人民公社生产规划地图的跟制，可以为 大、中比例尺的經济地图工作开辞道路，通过研究士洋护举的工莱配置的新布局，可 以为建立全新的工栄地理学打好基础; 通过对于基本农田制、闰林化和农策工厂化的

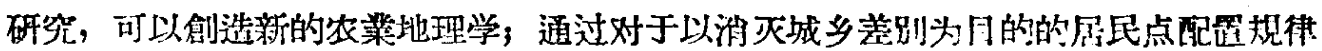
的研究, 可以創立澵的共产主义的人口地理学。这些科学都將是我国地理界所独創, 不仅在国內，而且对所有走向共产主义的国家都有重要的实路意义。

除了人民公社以外，我們認为地区規划和区划工作，仍然是桱济地理工作的正确 方向。我椚过去循着这个方向做了不少工作，但帕于我們的工作方式和工作方法存在 着一些問題，因而影响到工作的成效。今后在改变工作方式、革新工作方法的前提下

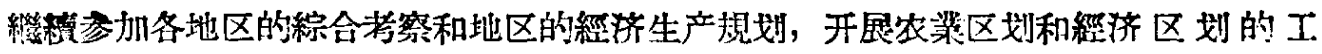
作。”包公耐地可說是小区規划的一个新內容，在理論和灾践上都可以和区划和規划 工俳結合起来，由下而上，由上而下，大中小結合，互相逐逐，互相丰䈏。

搞人民公㣂和小区域典型調查，又是对过去我們落后的工作方式和方法“对痽下 荡”的措施; 通过这些工作实践，我們可以改变过去的大区“跑查”的方式为小区“定枯” 的方式，改变过去“广种櫵收”的做法为“精耕細作”的做法，而且由于人民公社是新䦓 题, 住理論和方法上都无成規可套, 因陑必然可以克服教条主义的毛病。

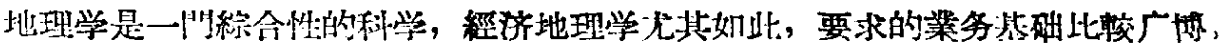

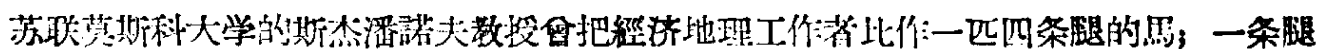

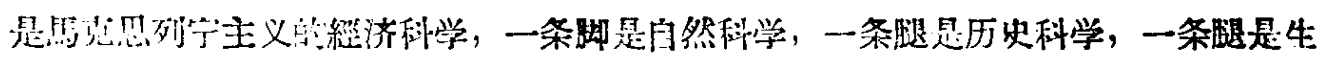

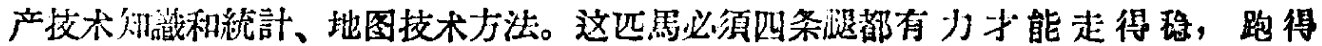


快。很显然，我們要改变維济地理学的落后面貌，必須 从根本做越，那就是我們工作同志本身要在政治思想 上、在羓务上、在技术上各方面充实我們的基础，提 高我們的修养。在今后我們的任何工作中必須坚持向 棸众学习的原则, 随时总結, 加速提高。

我們各單位的經济地理工作同志，大芜有决心㪗 足千勁, 通力合作, 在今后三、五年內, 在解决生产 实际開題的基础上建立我国的农粱地理学、工筑地理 学和綜合性的人民公社經济地理学。

\section{关于人民公新灌湘問題的研究}

农村的人民公社化，給农策生产和灌溉工作带来 了湈新的面貌和要求，保 既农作物高額丰产，实現 “少种多收”和机珹化电气化，是人民公社整个农菜生 产的奋斗目标。具体到灌溉問題上, 要求(一)杜紹早 合, 合理与經济用水, 保证农作物丰收，(二)从現有 灌源渠道布置上滿足农栄机械化要求; (三)改进現有 的各种灌水技术措施, 如灌水方法、工具、組織等, 以大大提高灌水的劳动生产率。

为了上述目的, 水利科学研究院对河南新乡的七 里营和小學人民公社(現合件为一个公社, 拥有耕地 14 万亩, 以种植棉麦为主, 引橫河人民泩利渠灌溉） 五年来在生产笑践上积照的經驗(包 括 农萧生产合作 社与人民公社时期)和 兩 年来本院与引黃灌溉管理局 和兩个公社合作的試驗研究成果进行了綜合, 写成了 “七里营(小䔬)人民公致灌激好”一䡒。半于1958 年 11 月在当地党委領导下, 进行了七里营人民公滆共 产主义新农村水利規划, 写成了有关这一問題的專門 报告。前一䡒里的主要內容有8田間渠道的改建, 监 时渠的应用, 农田治港, 提高水的有效利用系数, 改

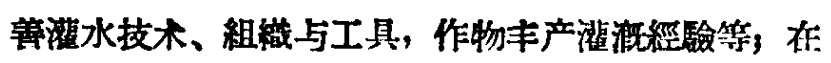
后一份拫告里, 主要內容有: (一)全面用水的規划, （二）公社內河网化与灌激渠系的規划, (三)应用新式 灌水方法的規划。

在工作中主要岄确了以下各点:

（一）在公社进行水利規划时，应 当策雇农粱和 工策各方面对水的要求。

(二) 在旱作物地区实現以 为主的河网化后, 在調配水量时, 应使地下水位在雨季时也保持在一公 尺以下。

（三）末极固定梁的布置保䫏 农 策机械化与地形 的要求, 在以棉考为主的公社, 这般渠道控制地段的 适宜尺寸是， 400-800、䙾 200-400 公尺。

（四）适应棉麦地区农業机械化的田間渠柔, 应 实行临时灌激网。为了滿足园田化的要求, 目前采月了 利密的布置(辰 200-400 公尺, 間距 30-60 公尺)。

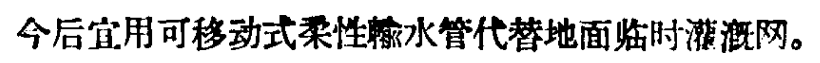

（五）解决平原地区人民会社的內港，应实現河 网化，为了保証棉花等秋作高額丰产，河网閒也应考 虑排水。目前, 比較簡便經济的办法是实行田開灌渐 网的灌排兩鿟。

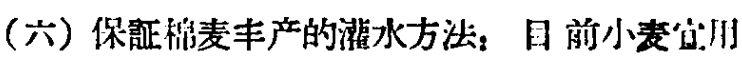

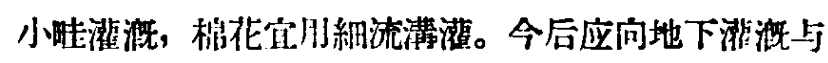
唶灌相結合的方向发展。

（七）介程了原小翼人民公䎟高庭經济川水(支渠 水的有效利月系数达到 0.78, 农渠达到 0.90-0.95) 的整漈綜合措施。

人民公塥是最近才发展成的农村基层組織, 它对 农田灌溉所带来的深刻变化、新的要求和解决措施, 还有待于今后各方面的深入研討。

\section{水利科学研究院}

\section{帮助人民公社做規划}

人民公部的研究將成为发展我国地理科学的一项 重要任务, 不論自然地理和經济地理都可以在做人民 公社的規划中与生产实践結合起来, 井以此任务帶动 学科的发展。

我們會到永吉县江密唩人民公佂开展了与地理有 关的比較全面的工作，扑为公档做出了农林牧副漁及 工㫧、居民点等 10 多个测划。例如我們了解了該区 地下水的分布規律和河流的水文規律，根据公矿的意 图, 制定了河网化和州网化为主的排萑系統規划。現 在他們按照这一規划, 进行水利化的措施, 全面地利

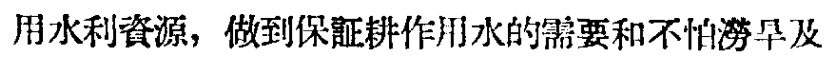
利用水力发电来考虑电气化的具体措施。此外, 植物

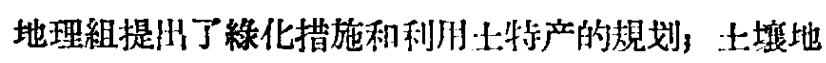
理組提山改良土壤和施萌詀划, 未进行了深彩的研

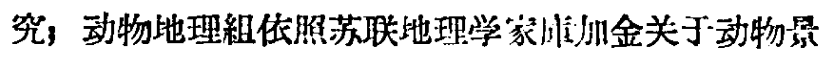
覌学的理論也提出了消灭鼠害的措施。在經济地理方 面也为公社解决了一些具体問題, 例如双辽县由于生 产的需要, 要从县北迁移 5 万人到县南, 由于及时地 做川了居民点的規划, 从而解决了迁移中所产生的泪 难，又如双辽县根据多种經营与荊但一生产相結合的生

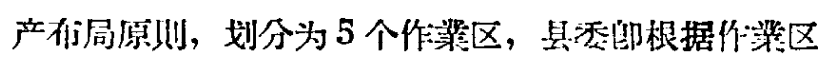
調整了行政区划，以利偵导生产。

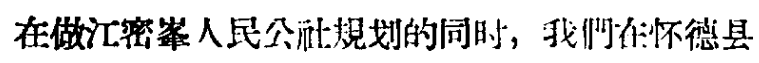

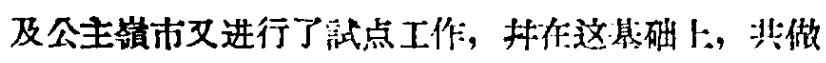
了14 个县方的规划。

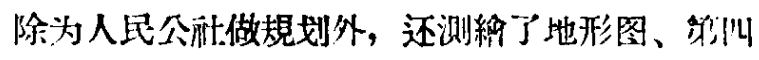

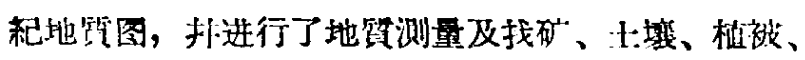
动物地理和經济地理等調李。

中国科学院吉林分院地理研究所 